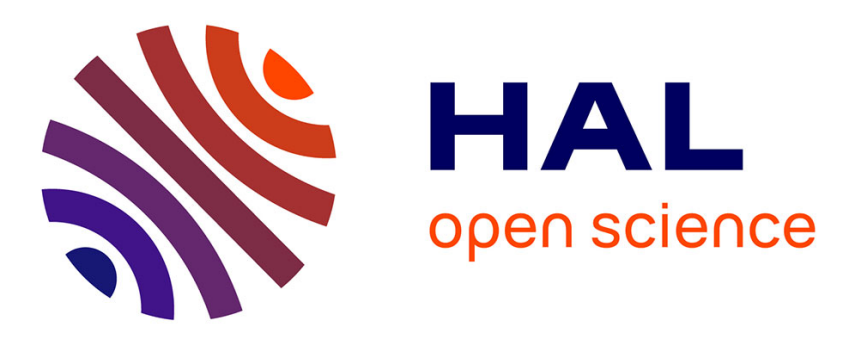

\title{
Effects of carbon on the magnetism of EuB6
}

Mitsuo Kasaya, Jean-Marie Tarascon, Jean Etourneau, Paul Hagenmuller, J.

M. D. Coey

\section{To cite this version:}

Mitsuo Kasaya, Jean-Marie Tarascon, Jean Etourneau, Paul Hagenmuller, J. M. D. Coey. Effects of carbon on the magnetism of EuB6. Journal de Physique Colloques, 1979, 40 (C5), pp.C5-393-C5-394. 10.1051/jphyscol:19795143 . jpa-00218930

\section{HAL Id: jpa-00218930 https://hal.science/jpa-00218930}

Submitted on 1 Jan 1979

HAL is a multi-disciplinary open access archive for the deposit and dissemination of scientific research documents, whether they are published or not. The documents may come from teaching and research institutions in France or abroad, or from public or private research centers.
L'archive ouverte pluridisciplinaire HAL, est destinée au dépôt et à la diffusion de documents scientifiques de niveau recherche, publiés ou non, émanant des établissements d'enseignement et de recherche français ou étrangers, des laboratoires publics ou privés. 


\title{
Effects of carbon on the magnetism of $\mathbf{E u B}_{6}$
}

\author{
M. Kasaya (*), J. M. Tarascon, J. Etourneau and P. Hagenmuller \\ Laboratoire de Chimie du Solide du C.N.R.S., Université de Bordeaux 1, 33405 Talence, Cedex, France
}

and J. M. D. Coey

Groupe des Transitions de Phases, C.N.R.S., 38042 Grenoble, Cedex, France

\begin{abstract}
Résumé. - Des mesures d'aimantation ont été effectuées en fonction de la température et du champ magnétique pour divers échantillons $\mathrm{EuB}_{6-x} \mathrm{C}_{x}$. Pour $x=0$ et $x=0,21$ les composés sont respectivement ferromagnétique et antiferromagnétique. Pour des compositions intermédiaires, ils sont mictomagnétiques.
\end{abstract}

\begin{abstract}
Magnetization has been measured as function of temperature and magnetic field for compounds of composition $\mathrm{EuB}_{6-x} \mathrm{C}_{x}(0 \leqslant x \leqslant 0.21)$. It is suggested that samples with $x=0$ and 0.21 are ferromagnetic and antiferromagnetic, respectively, whereas those with intermediate composition are mictomagnets.
\end{abstract}

In a recent paper on the influence of carbon donors on the physical properties of europium hexaboride [1] it was reported that the dominant magnetic interaction in $\mathrm{EuB}_{6-x} \mathrm{C}_{x}$ changes from ferromagnetic to antiferromagnetic with increasing carbon content; the paramagnetic Curie temperature decreased progressively from 15 to $-6.5 \mathrm{~K}$ as $x$ increased from 0 to 0.21 . The $\mathrm{EuB}_{6-x} \mathrm{C}_{x}$ system, in contrast with $\mathrm{Eu}_{1-x} \mathrm{R}_{x} \mathrm{~B}_{6}(\mathrm{R}=\mathrm{La}, \mathrm{Gd}, \mathrm{Yb})$, has no disorder in the cation sublattice and is therefore an ideal material in which to study the influence of conduction electrons on magnetism. In view of this we decided to obtain the magnetic ordering temperatures $T_{0}$ and attempt to establish the magnetic phase diagram of the system, by measuring magnetization as function of temperature and magnetic field for $x=0,0.05,0.054,0.082$, 0.139 and 0.21 . The purpose of the present paper is to report the results of these observations.

The sintered samples used in these experiments were prepared by borothermal reduction [1]. Magnetization curves at $4.2 \mathrm{~K}$ under magnetic fields up to $150 \mathrm{kOe}$ are summarized in figure $1\left(^{1}\right)$. In the figure we have taken into account demagnetization field of $\frac{4}{3} \pi M$ (3.7 kOe for $7 \mu_{\mathrm{B}} / \mathrm{Eu}$ ion), assuming that each particle in the powder has a spherical form. Strictly speaking, the demagnetizing factor may vary from 0 to $4 \pi$.

We discuss first the magnetization curve for $x=0$. It saturates readily and gradual increase of magnetization at low field may be due to the spread of demagnetizing field and also to the increase of magnetic moment from its thermal average value at $4.2 \mathrm{~K}$

$\left(^{*}\right)$ Permanent address : Department of Physics, Faculty of Science, Tohoku University, Sendai, Japan.

( ${ }^{1}$ ) This data was obtained at the Service National des Champs Intenses, Grenoble.

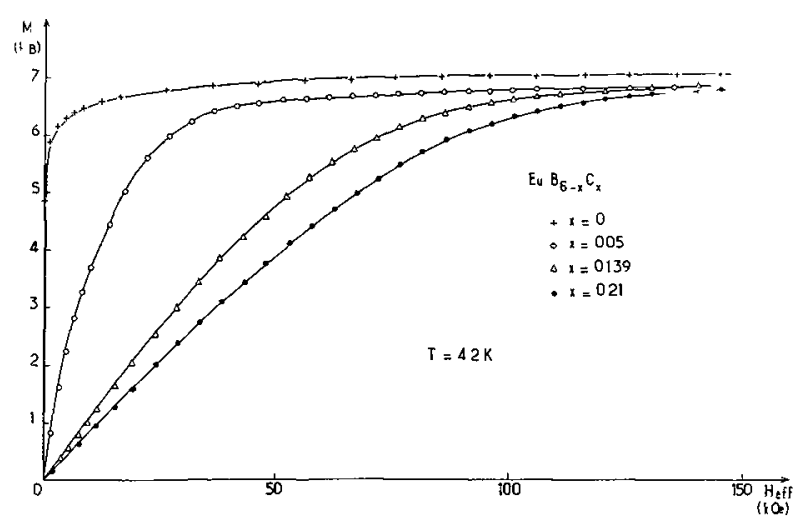

Fig. 1. - Variation of the magnetization as the function of field.

to $7 \mu_{\mathrm{B}}$. The curve is therefore characteristic of a ferromagnet whose Curie temperature $T_{\mathrm{C}}$ is found to be $12.0 \mathrm{~K}$ and $12.5 \mathrm{~K}$ from Arrott plots and Mössbauer effect [2], respectively. In contrast, for $x=0.21$, the magnetization increases linearly with increasing magnetic field up to $20 \mathrm{kOe}$, above which it approaches gradually its saturation value. In the present system all the $\mathrm{Eu}$ ions are in the $\mathrm{Eu}^{2+}(L=0)$ state [2] and the anisotropy energy $H_{\mathrm{A}}$ should be small compared to the exchange field $H_{\mathrm{E}}$. In such a case, the magnetization of an antiferromagnetic powder increases nearly linearly with increasing magnetic field at low field and there is no abrupt change from antiferromagnetic to ferromagnetic spin alignment. The magnetization curve for $x=0.21$ may be consistent with this scheme. A negative value of the paramagnetic Curie temperature, $-6.5 \mathrm{~K}$, also suggests that the $x=0.21$ sample is antiferromagnetic. Temperature dependence of the magnetization for $x=0.21$ at 
$1.2 \mathrm{kOe}$ is included in figure 2 . In fact there is a small peak at $7.3 \mathrm{~K}$ which is observable even at $10 \mathrm{kOe}$. For an antiferromagnet, the susceptibility at $T_{\mathrm{N}}$ is

$$
\chi\left(T_{\mathrm{N}}\right)=1 / A
$$

where $A$ is the molecular field coefficient, given by

$$
A=6 k T_{\mathrm{N}} / N g^{2} \mu_{\mathrm{B}}^{2} S(S+1) .
$$

Putting values of $T_{\mathrm{N}}=7 \mathrm{~K}$ and $S=7 / 2$ into eq. (1), we obtain $\chi\left(T_{\mathrm{N}}\right)$ of $0.56 \mathrm{emu} / \mathrm{mole}$, which is reasonable compared to the experimental value of $0.47 \mathrm{emu} / \mathrm{mole}$. From these facts we conclude that the sample with $x=0.21$ is an antiferromagnet with $T_{\mathrm{N}}=7.3 \mathrm{~K}$.

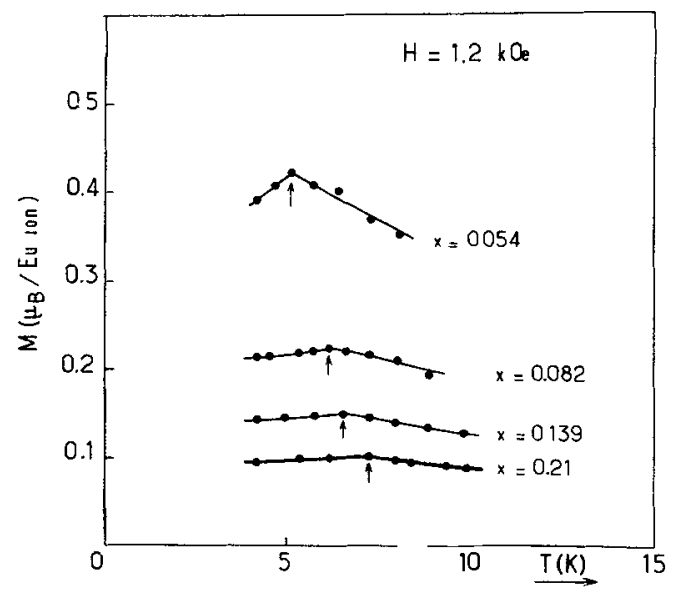

Fig. 2. - Temperature dependence of magnetization of $\mathrm{EuB}_{6-x} \mathrm{C}_{x}$ compounds.

Finally we discuss the magnetic properties of EuB $_{6-x} \mathrm{C}_{x}$ for intermediate values of $x$. As typical examples, we show magnetization curves at $4.2 \mathrm{~K}$ for $x=0.05$ and 0.139 in figure 1 . The curve for $x=0.139$ is essentially same as that for $x=0.21$. However the curve for $x=0.05$ is different from those for $x=0$ and 0.21 . At low fields the susceptibility is field dependent and saturation of the magnetization is obtained above $50 \mathrm{kOe}$. Temperature dependences of magnetization at $H=1.2 \mathrm{kOe}$ for $x=0.054$, 0.082 and 0.139 are given in figure 2. There is a peak in the magnetization $v s$ temperature curve. This peak occurs at $5.1 \mathrm{~K}$ for $x=0.054$ and shifts toward higher temperature with increasing $x$. It is worthwhile to note that for $x=0.054$ the peak is observable under magnetic fields up to $3.6 \mathrm{kOe}$, but at higher magnetic fields it disappears. The magnetic ordering temperature for $x=0.05$ obtained from Mössbauer effect is $5.2 \mathrm{~K}$ [2]. A peculiar feature of the Mössbauer data is the line width for $x=0.05$ at $4.2 \mathrm{~K}$ which, in contrast to $x=0$ or 0.21 , is very broad. This suggests that the exchange interactions are inhomogeneous. From these facts there is a strong possibility that the magnetic order of $\mathrm{EuB}_{6-x} \mathrm{C}_{x}$ with $x=0.05$ is mictomagnetic [3].

Based on the experimental results described above, we show the magnetic phase diagram of $\mathrm{EuB}_{6-x} \mathrm{C}_{x}$ system in figure 3 . From our experimental results it appears that the zone marked with a query corresponds to a mictomagnetic phase.

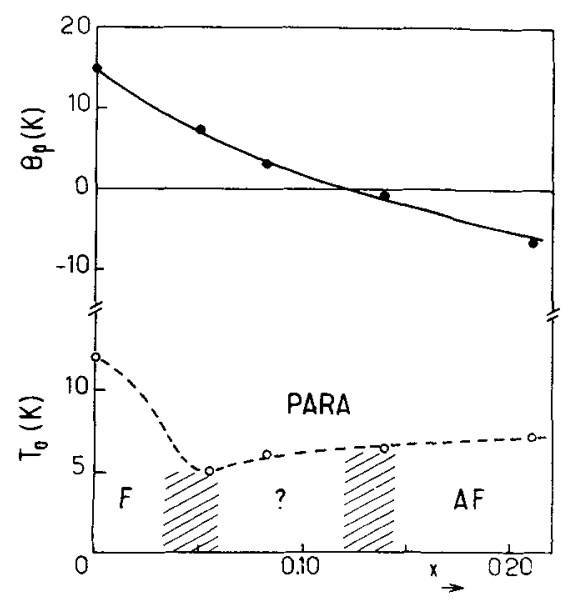

Fig. 3. - Variation of the magnetic ordering temperature and magnetic phase diagram for $\mathrm{EuB}_{6-x} \mathrm{C}_{x}$ as a function of $x$. For comparison the paramagnetic Curie temperature is also shown in the upper part of the figure.

\section{References}

[1] Kasaya, M., Tarascon,'J. M., Etourneau, J. and HagenMULler, P., Mat. Res. Bull. (1978) to be published.

[2] Coey, J. M. D., Massenet, O., Kasaya, M. and Etourneau, J., Proc. Int. Conf. on Mössbauer Effect, Kyoto (1978). To be published in $J$. Physique Colloq.

[3] Beck, P. A., Metal Trans. 2 (1971) 2015. 